\title{
Diagnostic Reference Levels based on clinical indications in computed tomography: a literature review
}

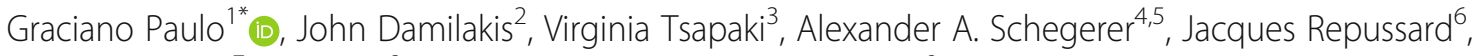
Werner Jaschke ${ }^{7}$, Guy Frija ${ }^{8}$ and European Society of Radiology ${ }^{9}$

\begin{abstract}
Background: In August 2017, the European Commission awarded the "European Study on Clinical Diagnostic Reference levels for X-ray Medical Imaging" project to the European Society of Radiology, to provide up-to-date Diagnostic Reference Levels based on clinical indications.

The aim of this work was to conduct an extensive literature review by analysing the most recent studies published and the data provided by the National Competent Authorities, to understand the current situation regarding Diagnostic Reference Levels based on clinical indications for computed tomography.

Results: The literature review has identified 23 papers with Diagnostic Reference Levels based on clinical indications for computed tomography from 15 countries; 12 of them from Europe.

A total of 28 clinical indications for 6 anatomical areas (head, cervical spine/neck, chest, abdomen, abdomen-pelvis, chest-abdomen-pelvis) have been identified.

Conclusions: In all the six anatomical areas for which Diagnostic Reference Levels based on clinical indications were found, a huge variation of computed tomography dose descriptor values was identified, providing evidence for a need to develop strategies to standardise and optimise computed tomography protocols.
\end{abstract}

Keywords: Diagnostic Reference Levels, Computed tomography, Clinical indications, Computed tomography dose descriptors

\section{Key points}

- The establishment, regular review and use of Diagnostic Reference Levels are mandatory according to the Council Directive 2013/59/ EURATOM.

- Most of the existing Diagnostic Reference Levels have been established based on anatomical locations, which has some limitations as one could have several clinical indications with consequently

\footnotetext{
* Correspondence: graciano@estescoimbra.pt

'ESTESC - Coimbra Health School, Medical Imaging and Radiotherapy Department, Instituto Politécnico de Coimbra, Rua 5 de Outubro, S. Martinho do Bispo, 3046-854 Coimbra, Portugal

Full list of author information is available at the end of the article
}

different protocols corresponding to different exposure levels.

- In the anatomical areas for which Diagnostic Reference Levels based on clinical indications were found, a huge variation of computed tomography dose descriptors values has been identified.

- The EUCLID project aims to establish Diagnostic Reference Levels based on clinical indications.

\section{Background}

The concept of Diagnostic Reference Levels (DRLs) was introduced many years ago by the International Commission on Radiological Protection (ICRP) [1] and has been widely accepted as a practical tool for optimisation in diagnostic and interventional radiology and nuclear

\section{Springer Open}

(C) The Author(s). 2020 Open Access This article is licensed under a Creative Commons Attribution 4.0 International License which permits use, sharing, adaptation, distribution and reproduction in any medium or format, as long as you give appropriate credit to the original author(s) and the source, provide a link to the Creative Commons licence, and indicate if changes were made. The images or other third party material in this article are included in the article's Creative Commons licence, unless indicated otherwise in a credit line to the material. If material is not included in the article's Creative Commons licence and your intended use is not permitted by statutory regulation or exceeds the permitted use, you will need to obtain permission directly from the copyright holder. To view a copy of this licence, visit http://creativecommons.org/licenses/by/4.0/. 
medicine. DRLs should be used as a form of investigation level to identify unusually high dose levels. If DRLs are consistently exceeded, a local review usually takes place. DRLs are not intended for regulatory or commercial purposes, nor do they represent a dose constraint, nor are they linked to limits or constraints [2].

The European Union has formally introduced the concept and the mandatory use of DRLs in every Member State since 1997 [3], reinforcing the obligation for the establishment, regular review and use in 2013 through the Council Directive 2013/59/EURATOM (BSSD), on health protection of individuals against the dangers of ionising radiation in relation to medical exposure [4].

Most of the existing DRLs (independently of the imaging modality) have been established based on anatomical locations. However, some limitations of this approach were pointed out for computed tomography (CT) as, for the same anatomical location, one could have several clinical indications with consequently different protocols corresponding to different exposure levels. For example, chest CT could correspond to the work-up for pulmonary embolism, lung cancer, or even coronary calcium scoring, each of which requires corresponding image quality parameters and scan length, and hence should have different DRLs [5].

The clinical approach to DRLs was mentioned some years ago by the ICRP [6], but most of the European $\mathrm{Na}$ tional Competent Authorities (NCAs) still consider DRLs for anatomical location and not for clinical indication. However, some countries have recently established DRL based on clinical indications $\left(\mathrm{DRL}_{\mathrm{ci}}\right)$ and some others are planning to do so in the near future. Also the European Society of Radiology (ESR) EuroSafe Imaging Call for Action 2018 has defined the objective to develop $\mathrm{DRL}_{\mathrm{ci}}$ for adults and children, under action number 2 [7].

In this work, the dose descriptors used to define a DRL in CT are (a) volume computed tomography dose index $\left(\mathrm{CTDI}_{\mathrm{vol}}\right)$, the standard descriptor for estimating the output dose of a CT scanner, based on measurements obtained when scanning either a $16 \mathrm{~cm}$ or $32 \mathrm{~cm}$ phantom [8] and the unit used is mGy; (b) dose length product total $\left(\mathrm{DLP}_{\mathrm{t}}\right)$, which is the sum of the DLP values from each $\mathrm{CT}$ acquisition/phase, representing the measure of the total amount of radiation used to perform the CT examination. DLP is the product of the CTDI ${ }_{\mathrm{vol}}$ (mGy) and scan length $(\mathrm{cm})$, and the unit used is mGy.cm.

Both CTDI $\mathrm{vol}_{\mathrm{vol}}$ and DLP $\mathrm{t}_{\mathrm{t}}$ are essential tools for CT optimisation; however it is important to understand the fact that they only represent CT scanner output and consequently are not patient dose estimates [9].

In August 2017, the European Commission (EC) launched the "European Study on Clinical Diagnostic
Reference Levels for X-ray Medical Imaging" (EUCLID) project, to provide up-to-date $\mathrm{DRL}_{\mathrm{CI}}$.

The main objectives of the EUCLID project, led by the ESR, were to conduct a European survey to collect data needed for the establishment of $\mathrm{DRL}_{\mathrm{ci}}$ for the most important X-ray imaging tasks in Europe (from the radiation protection perspective) and to specify up-to-date $\mathrm{DRL}_{\mathrm{ci}}$ for those examinations.

The aim of this work was to conduct an extensive literature review by analysing the most recent studies published and the data provided by NCAs, to understand the current situation regarding $\mathrm{DRL}_{\mathrm{ci}}$ for $\mathrm{CT}$, under the scope of EUCLID project.

\section{Materials and methods}

One of the goals of EUCLID was the collection of information on the status of national DRLs and DRL $\mathrm{ci}_{\mathrm{i}}$ in Europe from NCAs from literature and from a workshop held in December 2019 in Luxembourg. The methodology for this included contacting the NCAs of 31 European countries and asking them to provide available national data that was then discussed and confirmed during the aforementioned workshop. Additionally, a comprehensive literature review was undertaken in order to identify which clinical indications had already been specifically studied.

To perform the literature review, several databases were used, such as science direct, PubMed and Google Scholar. Multiple keywords combination was used, such as diagnostic reference levels in computed tomography, clinical diagnostic reference levels and diagnostic reference levels based on clinical indications. All publications were collected and stored in the Mendeley reference management software (www.mendeley.com).

\section{Results}

Literature review for $\mathrm{DRL}_{\mathrm{ci}}$ in CT

By using the keywords defined, data from 65 papers was considered and amongst them 23 included $\mathrm{DRL}_{\mathrm{c}}$, being that 3 of them were from countries outside Europe (United States of America, Japan and Egypt) and 12 from European countries: Austria, Denmark, Finland, France, Germany, Ireland, Italy, Norway, Sweden, Switzerland, The Netherlands, United Kingdom. In addition, data provided by the NCAs, discussed and validated during the workshop, were also included.

Considering that the concept of $\mathrm{DRL}_{\mathrm{ci}}$ is a recent one, some discrepancy and inconsistency was found in the classification of the clinical indication.

The DRLci values found were for several anatomical areas and are listed in Table 1 . A total of 28 clinical indications for 6 anatomical areas have been identified. The anatomical areas with the most values for $\mathrm{DRL}_{\mathrm{ci}}$ were "head" and "abdomen", with a total of 6 each. 
Table $1 \mathrm{CT}$ clinical indications

\begin{tabular}{|c|c|}
\hline Anatomical area & Clinical indication \\
\hline \multirow[t]{6}{*}{ Head: $n_{\mathrm{ci}} 6$} & Acute stroke \\
\hline & Haemorrhage/aneurysms/arteriovenous malformations \\
\hline & Metastases/cerebral abscess \\
\hline & Trauma \\
\hline & Cholesteatoma \\
\hline & Sinusitis \\
\hline \multirow[t]{3}{*}{ Cervical (spine and neck): $n_{\mathrm{ci}} 3$} & Fracture \\
\hline & Disk pathology \\
\hline & Adenopathy/abscesses \\
\hline \multirow[t]{5}{*}{ Chest: $n_{\mathrm{ci}} 5$} & Lung cancer \\
\hline & Interstitial lung disease \\
\hline & Pulmonary embolism \\
\hline & Coronaries (CTC angiography) \\
\hline & Coronaries (calcium scoring) \\
\hline \multirow[t]{6}{*}{ Abdomen: $n_{\mathrm{ci}} 6$} & Liver metastases \\
\hline & Abscess \\
\hline & Kidney stones/colic \\
\hline & Kidney tumour/colic \\
\hline & Acute abdomen \\
\hline & Pancreas adenocarcinoma \\
\hline \multirow[t]{5}{*}{ Abdomen-pelvis: $n_{\mathrm{ci}} 5$} & Abscess/lymphadenopathy \\
\hline & Virtual colonoscopy (polyps/tumour) \\
\hline & Abdominal aorta angiography \\
\hline & Colic \\
\hline & Occlusion \\
\hline \multirow[t]{3}{*}{ Chest-abdomen-pelvis: $n_{\mathrm{ci}} 3$} & Tumour \\
\hline & Infectious \\
\hline & Oncologic follow-up \\
\hline
\end{tabular}

\section{Head CT}

For head CT, 10 references with $\mathrm{DRL}_{\mathrm{ci}}$ were found for 6 clinical indications: acute stroke; haemorrhage/aneurysms/arteriovenous malformations; metastases/cerebral abscess; trauma; cholesteatoma; sinusitis. Table 2 shows the $\mathrm{DRL}_{\mathrm{ci}}$ for head CT with the CTDI ${ }_{\mathrm{vol}}$ and/or DLP values for each clinical indication. The $\mathrm{DRL}_{\mathrm{ci}}$ for trauma/sinusitis was the clinical indication with the most references found (7 out of 10). The DLP values ranged from 90 mGy.cm [14] to 1000 mGy.cm [18]. One publication presents $\mathrm{DRL}_{\mathrm{ci}}$ for head CT both for males and females [16], demonstrating however similar or in some cases equal values.

\section{Cervical (spine and neck) CT}

For cervical (spine and neck) CT, eight references with $\mathrm{DRL}_{\mathrm{ci}}$ were found for three clinical indications: fracture, disk pathology and adenopathy/abscess. Table 3 shows the $\mathrm{DRL}_{\mathrm{ci}}$ for cervical (spine and neck) CT with the $\mathrm{CTDI}_{\mathrm{vol}}$ and/or DLP values for each clinical indication. The $\mathrm{DRL}_{\mathrm{ci}}$ for fracture was the clinical indication with more references found (six out of eight). The DLP values ranged from $300 \mathrm{mGy} . \mathrm{cm}$ [18] to $640 \mathrm{mGy.cm}$ [15]. One publication presents $\mathrm{DRL}_{\mathrm{ci}}$ for head CT both for males and females [16], however, with similar values. Two publications from the same country, one from 2016 [11] and other from 2018 [19], show a reduction of DLP values from $600 \mathrm{mGy} . \mathrm{cm}$ to $440 \mathrm{mGy} . \mathrm{cm}$ for the same clinical indication "fracture".

\section{Chest CT}

For chest CT, 23 references with $\mathrm{DRL}_{\mathrm{ci}}$ were found for 6 clinical indications: lung cancer, interstitial lung disease, pulmonary embolism, coronary computed tomography angiography (CCTA), calcium scoring. Table 4 shows the $\mathrm{DRL}_{\mathrm{ci}}$ for chest CT with the $\mathrm{CTDI}_{\mathrm{vol}}$ and/or DLP 


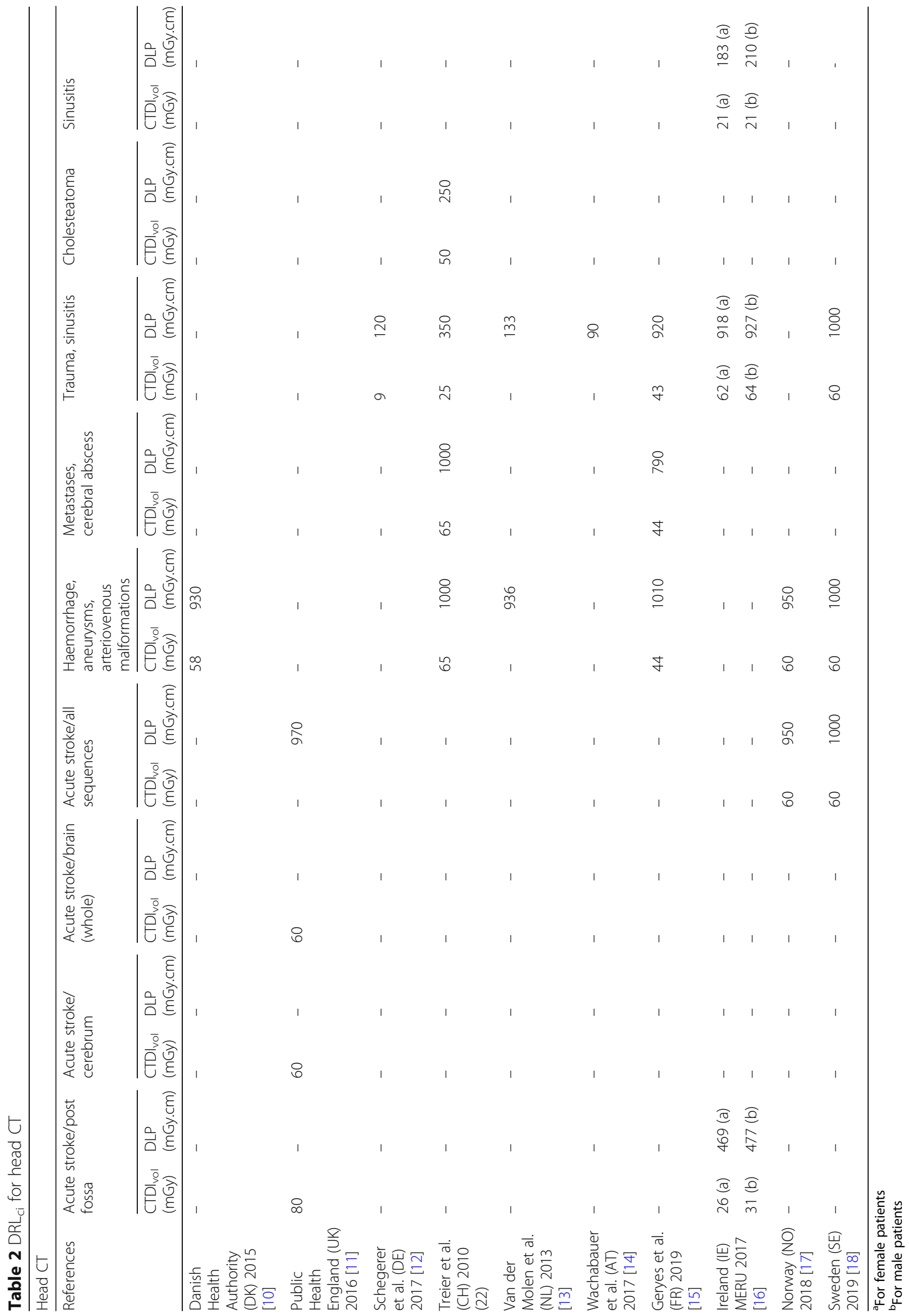


Table $3 D^{D R} L_{c i}$ for cervical $C T$

\begin{tabular}{|c|c|c|c|c|c|c|}
\hline \multicolumn{7}{|l|}{ Cervical CT } \\
\hline \multirow[t]{2}{*}{ References } & \multicolumn{2}{|l|}{ Fracture } & \multicolumn{2}{|l|}{ Disk pathology } & \multicolumn{2}{|c|}{ Adenopathy, abscesses } \\
\hline & $\mathrm{CTDI}_{\mathrm{vol}}$ (mGy) & $\mathrm{DLP}(\mathrm{mGy} . \mathrm{cm})$ & CTDI $_{\text {vol }}$ (mGy) & $\mathrm{DLP}$ (mGy.cm) & $\mathrm{CTDI}_{\mathrm{vol}}(\mathrm{mGy})$ & DLP (mGy.cm) \\
\hline Schegerer et al. (DE) 2019 [20] & 20 & - & 25 & - & - & - \\
\hline Public Health England (UK) 2016 [11] & 26 & 600 & - & - & - & - \\
\hline Treier et al. (CH) 2010 [21] & - & - & - & - & 30 & 600 \\
\hline Geryes et al. (FR) 2019 [15] & 31 & 640 & - & - & - & - \\
\hline \multirow[t]{2}{*}{ Ireland (IE) MERU 2017 [16] } & $26(a)$ & 469 (a) & - & - & - & - \\
\hline & 31 (b) & $477(b)$ & - & - & - & - \\
\hline Norway (NO) 2018 [17] & 15 & 350 & - & - & - & - \\
\hline Sweden (SE) 2019 [18] & 13 & 300 & - & - & 30 & 600 \\
\hline Public Health England (UK) 2018 [19] & 21 & 440 & - & - & - & - \\
\hline
\end{tabular}

${ }^{\mathrm{a}}$ For female patients

${ }^{\mathrm{b}}$ For male patients

values for each clinical indication. The $\mathrm{DRL}_{\mathrm{ci}}$ for CCTA was the clinical indication with more references found (11 out of 23). The DLP values ranged from 170 mGy.cm [12] to 1400 mGy.cm [22]. One publication presents $\mathrm{DRL}_{\mathrm{ci}}$ for CCTA [12] made with three different approaches: prospective, no padding, 170 mGy.cm (c); prospective, with padding, $280 \mathrm{mGy} . \mathrm{cm}$ (d); prospective, with gating, 380 mGy.cm (e). From the three approaches, the prospective, no padding technique is the one that provides the lowest DLP value (170 mGy.cm).

\section{Abdominal CT}

For abdominal CT, 11 references with $\mathrm{DRL}_{\mathrm{ci}}$ were found for 6 clinical indications: liver metastasis, abscess, kidney stones/colic, kidney tumour/colic, acute abdomen and pancreas adenocarcinoma. Table 5 shows the $\mathrm{DRL}_{\mathrm{ci}}$ for abdominal CT with the CTDI ${ }_{\mathrm{vol}}$ and/or DLP values for each clinical indication. The $\mathrm{DRL}_{\mathrm{ci}}$ for liver metastasis and kidney stone/colic were the clinical indications with more references found (6 out of 12). For liver metastasis, the DLP values ranged from 400 mGy.cm $[15,19]$ to 1423 mGy.cm [27]. For kidney stone/colic, the DLP values ranged from $200 \mathrm{mGy} . \mathrm{cm}$ [33] to $460 \mathrm{mGy} . \mathrm{cm}$ [18]. One publication presents $D R L_{c i}$ for abdominal CT, both for males and females [16], demonstrating however similar values.

\section{Abdominopelvic CT}

For abdominopelvic CT, five references with $\mathrm{DRL}_{\mathrm{ci}}$ were found for five clinical indications: abscess/lymphadenopathy, virtual colonoscopy (VC)/polyps/tumour, CT for abdominal aortic aneurysms (AAA), colic and occlusion. Table 6 shows the $\mathrm{DRL}_{\mathrm{ci}}$ for abdominopelvic CT with the CTDI ${ }_{\mathrm{vol}}$ and/or DLP values for each clinical indication. The $\mathrm{DRL}_{\mathrm{ci}}$ for abscess/lymphadenopathy was the clinical indication with more references found (four out of five). The DLP values ranged from 650 mGy.cm [11, $15,34]$ to 750 mGy.cm [18].

\section{Chest-abdominopelvic CT}

For chest-abdominopelvic CT, three references with $\mathrm{DRL}_{\mathrm{ci}}$ were found for three clinical indications: tumour, infectious and oncologic follow-up. Table 7 shows the $\mathrm{DRL}_{\mathrm{ci}}$ for chest-abdominopelvic CT with the $\mathrm{CTDI}_{\mathrm{vol}}$ and/or DLP values for each clinical indication. The $\mathrm{DRL}_{\mathrm{ci}}$ for tumour and oncologic follow-up were the clinical indications with more references found (two out of three). For tumour, the DLP values ranged from 870 mGy.cm [15] to 950 mGy.cm [35]. For oncologic followup, the DLP values ranged from 605 mGy.cm [36] to 970 mGy.cm [34]. One publication presents $\mathrm{DRL}_{\mathrm{ci}}$ for abdominal CT, both for males and females [16], demonstrating however similar values.

\section{Discussion}

To our knowledge, this is the first article to perform literature review for $\mathrm{DRL}_{\mathrm{ci}}$. Considering that $\mathrm{DRL}_{\mathrm{ci}}$ is a recent concept, it is understandable that only a limited number of papers was found in the literature and most of the proposed $\mathrm{DRL}_{\mathrm{ci}}$ came from the NCAs of 12 European countries.

In all the six anatomical areas where $\mathrm{DRL}_{\mathrm{ci}}$ were found, a huge variation of CT dose descriptors values was identified, providing evidence that different approaches/protocols are used to perform the CT procedure for the same clinical indication.

In the 28 clinical indications identified in the literature, the procedures with the highest differences in DLP values were head trauma (11-fold), CCTA (9-fold), liver metastasis (3-fold) and cervical fracture (2-fold).

The huge variations in the reported CT dose descriptors values for almost all the clinical indications 
Table $4 \mathrm{DRL}_{\mathrm{Ci}}$ for chest $\mathrm{CT}$

\begin{tabular}{|c|c|c|c|c|c|c|c|c|c|c|c|c|}
\hline \multicolumn{13}{|l|}{ Chest CT } \\
\hline \multirow[t]{2}{*}{ References } & \multicolumn{2}{|c|}{ Lung cancer } & \multicolumn{2}{|c|}{$\begin{array}{l}\text { Interstitial lung } \\
\text { disease (axial) }\end{array}$} & \multicolumn{2}{|c|}{$\begin{array}{l}\text { Interstitial lung } \\
\text { disease (helical) }\end{array}$} & \multicolumn{2}{|c|}{$\begin{array}{l}\text { Pulmonary } \\
\text { embolism }\end{array}$} & \multicolumn{2}{|l|}{ CCTA } & \multicolumn{2}{|c|}{ Calcium scoring } \\
\hline & $\begin{array}{l}\text { ctdi } \\
\text { (mgy) }\end{array}$ & $\begin{array}{l}\text { dlp } \\
\text { (mgy.cm) }\end{array}$ & $\begin{array}{l}\text { ctdivol } \\
\text { (mgy) }\end{array}$ & $\begin{array}{l}\text { dlp } \\
\text { (mgy.cm) }\end{array}$ & $\begin{array}{l}\text { ctdi } \\
\text { (mgy) }\end{array}$ & $\begin{array}{l}\text { dlp } \\
\text { (mgy.cm) }\end{array}$ & $\begin{array}{l}\text { ctdivol } \\
\text { (mgy) }\end{array}$ & $\begin{array}{l}\text { dlp } \\
\text { (mgy.cm) }\end{array}$ & $\begin{array}{l}\text { ctdi } \\
\text { (mgy) }\end{array}$ & $\begin{array}{l}\text { dlp } \\
\text { (mgy.cm) }\end{array}$ & $\begin{array}{l}\text { ctdivol } \\
\text { (mgy) }\end{array}$ & $\begin{array}{l}\text { dlp } \\
\text { (mgy.cm) }\end{array}$ \\
\hline Castellano et al. (UK) 2017 [22] & - & - & - & - & - & - & - & - & - & 173 & - & - \\
\hline $\begin{array}{l}\text { Danish Health Authority (DK) } \\
2015 \text { [10] }\end{array}$ & 16 & 620 & - & - & 13 & 500 & - & - & 29 & 230 & - & - \\
\hline Foley et al. (IE) 2012 [23] & - & - & 7 & 276 & - & - & 13 & 432 & - & - & - & - \\
\hline Fukushima et al. (JP) 2012 [24] & - & - & - & - & - & - & - & - & - & 1510 & - & \\
\hline Schegerer et al. (DE) 2019 [20] & - & - & - & - & - & - & - & - & 20 & $330(d)$ & - & \\
\hline Hausleiter et al. 2009 [25] & - & - & - & - & - & - & - & - & 69,6 & 1152 & - & \\
\hline $\begin{array}{l}\text { Japan Network for Research on } \\
\text { Medical Exposures (JP) } 2015 \\
{[26]}\end{array}$ & - & - & - & - & - & - & - & - & 90 & 1400 & - & - \\
\hline Kanal et al. (USA) 2017 [27] & - & - & - & - & - & - & 19 & 557 & - & - & - & - \\
\hline Mafalanka et al. (FR) 2015 [28] & - & - & - & - & - & - & - & - & - & 870 & - & - \\
\hline Palorini et al. (IT) 2014 [29] & - & - & - & - & - & - & - & - & - & 1208 & - & 131 \\
\hline $\begin{array}{l}\text { Public Health England (UK) } \\
2016 \text { [11] }\end{array}$ & 12 & 610 & 4 & 140 & 12 & 350 & 13 & 440 & - & - & - & - \\
\hline $\begin{array}{l}\text { Radiation and Nuclear Safety } \\
\text { Authority (FI) } 2013 \text { [30] }\end{array}$ & 11 & 430 & - & - & - & - & - & - & - & - & - & - \\
\hline Salama et al. (EG) 2017 [31] & - & - & - & - & 22 & 421 & - & - & - & - & - & - \\
\hline Schegerer et al. (DE) 2017 [12] & - & - & - & - & - & - & 15 & 300 & $\begin{array}{l}36(\mathrm{e}) \\
19(\mathrm{~d})\end{array}$ & $\begin{array}{l}551(e) \\
270(d)\end{array}$ & 8 & 119 \\
\hline Treier et al. (CH) 2010 [21] & - & - & - & - & - & - & - & - & - & 1000 & - & 150 \\
\hline $\begin{array}{l}\text { Van der Molen et al. (NL) } 2013 \\
\text { [13] }\end{array}$ & - & - & - & - & - & 276 & - & 371 & - & 671 & - & 51 \\
\hline $\begin{array}{l}\text { Wachabauer et al. (AT) } 2017 \\
\text { [14] }\end{array}$ & - & - & - & - & - & - & - & 400 & - & - & - & - \\
\hline Geryes et al. (FR) 2019 [15] & - & - & - & - & - & - & 8 & 310 & - & - & - & - \\
\hline \multirow[t]{2}{*}{ Ireland (IE) MERU 2017 [16] } & 7 (a) & 241 (a) & - & - & 7 (a) & 210 (a) & 9 (a) & 234 (a) & - & - & - & - \\
\hline & 7 (b) & 272 (b) & - & - & 7 (b) & 249 (b) & 12 (b) & 278 (b) & - & - & - & - \\
\hline Norway (NO) 2018 [17] & 9 & 350 & - & - & 9 & 300 & - & - & - & - & - & - \\
\hline Sweden (SE) 2019 [18] & 9 & 350 & - & - & - & - & - & & - & - & - & - \\
\hline \multirow{3}{*}{$\begin{array}{l}\text { Public Health England (UK) } \\
2018 \text { [19] }\end{array}$} & - & - & - & - & - & - & - & - & - & 170 (c) & - & - \\
\hline & - & - & - & - & - & - & - & - & - & $280(d)$ & - & - \\
\hline & - & - & - & - & - & - & - & - & - & $380(e)$ & - & - \\
\hline Netherlands (NL) 2012 [32] & - & - & - & - & - & - & 10 & 350 & - & - & - & - \\
\hline
\end{tabular}

addressed above are likely to be explained by differences in protocols (exposure parameters and scan length), type and age of scanner, number of acquisition series and, in the specific case of CCTA, by the option of performing either prospective or retrospective acquisitions. The same variations in radiation doses for CT across patients is described in the literature, and the reasons are primarily related on how CT scanners are used [34], the differences in patient's size (weight and height) [36] and to the level of image quality required to answer the clinical question [35]. Although the DRLs are defined for standard patients [4], taking into consideration that the weight and height of patients are also a determining factor 
Table $5 \mathrm{DRL}_{\mathrm{Ci}}$ for abdominal $\mathrm{CT}$

\begin{tabular}{|c|c|c|c|c|c|c|c|c|c|c|c|c|}
\hline \multicolumn{13}{|l|}{ Abdomen } \\
\hline \multirow[t]{2}{*}{ Reference } & \multicolumn{2}{|c|}{ Liver metastases } & \multicolumn{2}{|l|}{ Abscess } & \multicolumn{2}{|c|}{$\begin{array}{l}\text { Kidney stones/ } \\
\text { colic }\end{array}$} & \multicolumn{2}{|c|}{$\begin{array}{l}\text { Kidney tumour/ } \\
\text { colic }\end{array}$} & \multicolumn{2}{|c|}{ Acute abdomen } & \multicolumn{2}{|c|}{$\begin{array}{l}\text { Pancreas adeno } \\
\mathrm{Ca}\end{array}$} \\
\hline & $\begin{array}{l}\text { CTDI } \\
\text { (mGy) }\end{array}$ & $\begin{array}{l}\text { DLP } \\
\text { (mGy.cm) }\end{array}$ & $\begin{array}{l}\text { CTDI } \\
\text { (mGy) }\end{array}$ & $\begin{array}{l}\text { DLP } \\
\text { (mGy.cm) }\end{array}$ & $\begin{array}{l}\text { CTDI } \\
\text { (mGy) }\end{array}$ & $\begin{array}{l}\text { DLP } \\
\text { (mGy.cm) }\end{array}$ & $\begin{array}{l}\text { CTDI } \\
\text { (mGy) }\end{array}$ & $\begin{array}{l}\text { DLP } \\
(\mathrm{mGy} . \mathrm{cm})\end{array}$ & $\begin{array}{l}\text { CTDI }\left.\right|_{\text {vol }} \\
(\mathrm{mGy})\end{array}$ & $\begin{array}{l}\text { DLP } \\
\text { (mGy.cm) }\end{array}$ & $\begin{array}{l}\text { CTDI } \\
\text { (mGy) }\end{array}$ & $\begin{array}{l}\text { DLP } \\
\text { (mGy.cm) }\end{array}$ \\
\hline $\begin{array}{l}\text { Danish Health Authority } \\
\text { (DK) } 2015 \text { [10] }\end{array}$ & - & - & - & - & - & - & - & - & 17 & 700 & - & - \\
\hline $\begin{array}{l}\text { Public Health England } \\
\text { (UK) } 2016 \text { [11] }\end{array}$ & 14 & 910 & 15 & 745 & 10 & 460 & 13 & 1150 & - & - & - & - \\
\hline $\begin{array}{l}\text { Radiation and Nuclear } \\
\text { Safety Authority (FI) } 2013 \\
\text { [30] }\end{array}$ & - & - & - & - & 7 & 330 & - & - & - & - & - & - \\
\hline $\begin{array}{l}\text { Salama et al. (EG) } 2017 \\
\text { [31] }\end{array}$ & 31 & 1423 & - & - & - & - & - & - & - & - & - & - \\
\hline $\begin{array}{l}\text { Treier et al. (CH) } 2010 \\
\text { [21] }\end{array}$ & 15 & 400 & - & - & - & - & - & - & - & -- & - & - \\
\hline $\begin{array}{l}\text { Van der Molen et al. (NL) } \\
2013 \text { [13] }\end{array}$ & - & - & - & - & - & 329 & - & 1371 & - & - & - & 1000 \\
\hline $\begin{array}{l}\text { Wachabauer et al. (AT) } \\
2017 \text { [14] }\end{array}$ & - & 400 & - & - & - & - & - & - & - & - & - & - \\
\hline \multirow{2}{*}{$\begin{array}{l}\text { Ireland (IE) MERU } 2017 \\
\text { [16] }\end{array}$} & 9 (a) & 554 (a) & - & - & 6 (a) & 254 (a) & - & - & - & - & - & - \\
\hline & $10(b)$ & $515(b)$ & - & - & 8 (b) & 291 (b) & - & - & - & - & - & - \\
\hline Norway (NO) 2018 [17] & - & - & - & - & 5 & 250 & 13 & 1300 & - & - & - & - \\
\hline Sweden (SE) 2019 [18] & 11 & 550 & - & - & 5 & 200 & 12 & 1000 & - & - & - & - \\
\hline $\begin{array}{l}\text { Netherlands (NL) } 2012 \\
\text { [32] }\end{array}$ & - & - & - & - & - & - & - & - & 15 & 700 & - & - \\
\hline
\end{tabular}

${ }^{\mathrm{a}}$ For female patients

${ }^{\mathrm{b}}$ For male patients

for dose increase, categorising patients by body mass index should be considered in the near future [36].

Several other factors may also contribute to the heterogeneity of results shown in the $\mathrm{DRL}_{\mathrm{ci}}$ tables. DLP values may refer to individual sequences or to a complete examination (total DLP), and in some cases, this information is not included in the paper/report.

In addition, different names have been used for what is likely to have been the same indication (e.g. abscess versus acute abdomen), and the question of whether these differences are related to various interpretations of the name of the clinical indication or to different practices remains open. A semantic refinement, with the precise description of the clinical indication, should be made in the future in order to minimise any variation related to the meaning of the clinical indication.

For liver metastases and a few other clinical indications, $\mathrm{DRL}_{\mathrm{ci}}$ in terms of CTDI $\mathrm{vol}_{\mathrm{v}}$ are similar, but DRLs in terms of DLP differ considerably. The difference between results in values of total DLP (yet similar levels of

Table $6 \mathrm{DRL}_{\mathrm{Ci}}$ for abdomino-pelvis CT

\begin{tabular}{|c|c|c|c|c|c|c|c|c|c|c|}
\hline \multicolumn{11}{|l|}{ Abdomino-pelvis CT } \\
\hline \multirow[t]{2}{*}{ References } & \multicolumn{2}{|c|}{$\begin{array}{l}\text { Abscess } \\
\text { lymphadenopathy }\end{array}$} & \multicolumn{2}{|c|}{ VC-polyps/tumour } & \multicolumn{2}{|c|}{$\mathrm{CT}$ angiography (AAA) } & \multicolumn{2}{|l|}{ Colic } & \multicolumn{2}{|c|}{ Occlusion } \\
\hline & $\begin{array}{l}\text { CTDI }_{\text {vol }} \\
\text { (mGy) }\end{array}$ & $\begin{array}{l}\text { DLP } \\
\text { (mGy.cm) }\end{array}$ & $\begin{array}{l}\text { CTDI }_{\text {vol }} \\
\text { (mGy) }\end{array}$ & $\begin{array}{l}\text { DLP } \\
\text { (mGy.cm) }\end{array}$ & $\begin{array}{l}\text { CTDI }_{\text {vol }} \\
\text { (mGy) }\end{array}$ & $\begin{array}{l}\mathrm{DLP} \\
(\mathrm{mGy} . \mathrm{cm})\end{array}$ & $\begin{array}{l}\text { CTDI }_{\text {vol }} \\
(m G y)\end{array}$ & $\begin{array}{l}\text { DLP } \\
\text { (mGy.cm) }\end{array}$ & $\begin{array}{l}\text { CTDI } \\
\text { (mGy) }\end{array}$ & $\begin{array}{l}\mathrm{DLP} \\
(\mathrm{mGy} \cdot \mathrm{cm})\end{array}$ \\
\hline $\begin{array}{l}\text { Public Health England (UK) } \\
2016 \text { [11] }\end{array}$ & 15 & 745 & 11 & 950 & - & - & - & - & - & - \\
\hline Treier et al. (CH) 2010 [21] & 15 & 650 & - & - & 15 & 650 & - & - & - & - \\
\hline $\begin{array}{l}\text { Van der Molen et al. (NL) } \\
2013 \text { [13] }\end{array}$ & - & - & - & - & - & 727 & - & - & - & - \\
\hline $\begin{array}{l}\text { Wachabauer et al. (AT) } \\
2017 \text { [14] }\end{array}$ & - & 650 & - & - & - & - & - & - & - & - \\
\hline Geryes et al. (FR) 2019 [15] & - & 650 & - & - & - & - & 8 & 400 & 12 & 880 \\
\hline
\end{tabular}


Table $7 \mathrm{DRL}_{\mathrm{ci}}$ for chest-abdominopelvic CT

\begin{tabular}{|c|c|c|c|c|c|c|}
\hline \multicolumn{7}{|l|}{ Chest abdomen pelvis } \\
\hline \multirow[t]{2}{*}{ References } & \multicolumn{2}{|l|}{ Tumour } & \multicolumn{2}{|l|}{ Infectious } & \multicolumn{2}{|c|}{ Oncologic follow-up } \\
\hline & $\mathrm{CTDI}_{\mathrm{vol}}(\mathrm{mGy})$ & DLP (mGy.cm) & $\mathrm{CTDI}_{\mathrm{vol}}$ (mGy) & DLP (mGy.cm) & $\mathrm{CTDI}_{\mathrm{vol}}(\mathrm{mGy})$ & DLP (mGy.cm) \\
\hline Geryes et al. (FR) 2019 [15] & 10 & 870 & 11 & 970 & 11 & 970 \\
\hline \multirow[t]{2}{*}{ Ireland (IE) MERU 2017 [16] } & - & - & - & - & 8 (a) & 605 (a) \\
\hline & - & - & - & - & 8 (b) & $643(b)$ \\
\hline Norway (NO) 2018 [17] & 15 & 950 & - & - & - & - \\
\hline
\end{tabular}

${ }^{\mathrm{a}}$ For female patients

${ }^{\mathrm{b}}$ For male patients

$\mathrm{CTDI}_{\mathrm{vol}}$ ) for examinations of the lower trunk could be a consequence of the present use of increased scan lengths and/or number of sequences (particularly in relation to imaging for different phases in the distribution of contrast medium). The substantial variations in CT protocols, for the same clinical indication, delivers several folds higher radiation than necessary [33].

Although a large number of research studies have shown that dose optimisation tools such as tube current modulation can reduce patient dose considerably, it is not known how these tools are being used in everyday clinical practice. Large differences in dose descriptors for the same clinical indication and, sometimes, for the same CT scanner model may be addressed by standardising acquisition protocols, using dose reduction tools properly and improving education of practitioners in medical radiation protection.

\section{Conclusions}

From this literature review, it is obvious that there is a lot of space for improvement in terms of standardising the CT protocols for each clinical indication and that the development of European guidelines on this topic would be very useful as a tool to implement dose reduction strategies in CT procedures.

Continuing to develop DRLs for CT based in anatomical areas without taking into consideration the clinical indication will probably meet the minimum standard of the BSSD but will insufficiently contribute to fulfil the main purpose of the existence of DRLs: a tool for optimisation.

We expect that the results of this work can stimulate the radiological community and the NCAs to move toward the establishment of $\mathrm{DRL}_{\mathrm{ci}}$ in a more harmonised and consistent way.

\section{Abbreviations}

BSSD: Council Directive 2013/59/EURATOM; CT: Computed tomography; $C \mathrm{CDI}_{\text {vol }}$ : Volume computed tomography dose index; DLP: Dose length product total; DRL $\mathrm{L}_{\mathrm{i}}$ : DRL based on clinical indications; DRLs: Diagnostic Reference Levels; EC: European Commission; ESR: European Society of Radiology; EUCLID: European Study on Clinical Diagnostic Reference Levels for X-ray medical Imaging; ICRP: International Commission on Radiological Protection; NCAs: National Competent Authorities

\section{Acknowledgements}

The authors would like to acknowledge Ms. Monika Hierath and Mr. Jonathan Clark, staff members of the European Society of Radiology, for their outstanding contribution to this project.

\section{Authors' contributions}

All authors contributed to this paper, have read and approved the final manuscript.

\section{Funding}

The EUCLID project has received funding from the European Commission under Service Contract N ENER/2017/NUCL/SI2.759174.

Availability of data and materials

Not applicable

Ethics approval and consent to participate

Not applicable

\section{Consent for publication}

Not applicable

\section{Competing interests}

Not applicable

\section{Author details}

${ }^{1}$ ESTESC - Coimbra Health School, Medical Imaging and Radiotherapy Department, Instituto Politécnico de Coimbra, Rua 5 de Outubro, S. Martinho do Bispo, 3046-854 Coimbra, Portugal. ${ }^{2}$ School of Medicine, University of Crete, Iraklion, Crete, Greece. ${ }^{3}$ Konstantopoulio General Hospital, Athens, Greece. ${ }^{4}$ Department of Medical and Occupational Radiation Protection, Federal Office for Radiation Protection, Neuherberg, Germany. ${ }^{5}$ Radiation Protection and Image Processing Systems, Hirslanden AG, Glattpark, Switzerland. International Consultant, St Nom la Bretèche, France.

${ }^{7}$ Department of Radiology, Medical University Innsbruck, Innsbruck, Austria.

${ }^{8}$ Paris Descartes University, Paris, France. ${ }^{9}$ European Society of Radiology, Vienna, Austria.

Received: 17 June 2020 Accepted: 21 July 2020

Published online: 17 August 2020

\section{References}

1. (1997) Radiological protection and safety in medicine. A report of the International Commission on Radiological Protection. Ann ICRP 1996;26(2).

2. (2001) Diagnostic reference levels in medical imaging: review and additional advice. Ann ICRP 31(3):33-52

3. Council of the European Union (1997) Council Directive 97/43/Euratom of 30 June 1997 on health protection of individuals against the dangers of ionizing radiation in relation to medical exposure, and repealing Directive 84/466/Euratom. Official Journal of the European Union 1997 p. 22-27.

4. Council of the European Union (2013) Council Directive 2013/59/Euratom of 5 December 2013 laying down basic safety standards for protection against 
the dangers arising from exposure to ionising radiation, and repealing Directives 89/618/Euratom, 90/641/Euratom, 96/29/Euratom, 97/43/Euratom and 2003/122/Euratom. Official Journal of the European Union 2013 p. 1-73

5. Roch P, Célier D, Dessaud C, Etard C, Rehani MM (2019) Long-term experience and analysis of data on diagnostic reference levels: the good, the bad, and the ugly. Eur Radiol 30(2):1127-1136

6. Vañó E, Miller DL, Martin CJ et al (2017) Diagnostic reference levels in medical imaging. ICRP Publication 135. Ann ICRP 46(1):1-144

7. European Society of Radiology (ESR) (2018) Eurosafe imaging call for action. Available from: https://www.myesr.org/media/659

8. Bauhs JA, Vrieze TJ, Primak AN, Bruesewitz MR, McCollough CH (2008) CT dosimetry: comparison of measurement techniques and devices. RadioGraphics. 28(1):245-253 Available from: http://pubs.rsna.org/doi/10.114 8/rg.281075024

9. McCullough CH, Leng S, Yu L, Cody DD, Boone JM, McNitt-Gray MF (2011) CT dose index and patient dose. Radiology. 259(2):311-316

10. Danish Health Authority (2015) Ct Reference doser, Copenhagen

11. Public Health England (2016) National Diagnostic Reference Levels (NDRLs), vol 11 Available from: https://www.gov.uk/government/publications/ diagnostic-radiology-national-diagnostic-reference-levels-ndrls/nationaldiagnostic-reference-levels-ndrls\#fnref:2

12. Schegerer AA, Nagel HD, Stamm G, Adam G, Brix G (2017) Current CT practice in Germany: Results and implications of a nationwide survey. Eur J Radiol. 90:114-128 Available from: http://linkinghub.elsevier.com/retrieve/ pii/S0720048X17300669

13. van der Molen AJ, Schilham A, Stoop P, Prokop M, Geleijns J (2013) A national survey on radiation dose in CT in The Netherlands. Insights Imaging. 4(3):383-390 Available from: http://link.springer.com/10.1007/ s13244-013-0253-9

14. Wachabauer D, Röthlin F (2017) Aktualisierung der diagnostischen Referenzwerte für Österreich, Wien

15. Habib Geryes B, Hornbeck A, Jarrige V, Pierrat N, Ducou Le Pointe H, Dreuil $S$ (2019) Patient dose evaluation in computed tomography: A French national study based on clinical indications. Phys Medica 61:18-27 Available from: https://linkinghub.elsevier.com/retrieve/pii/S1120179719300808

16. MERU (2017) National survey on population dose from computed tomography 2017, Dublin

17. Widmark A. (2018) Diagnostic reference level (DRL) in Norway 2017. Available from: https://www.dsa.no

18. SRPA (2019) Diagnostic Reference Levels in the Swedish legislation. Available from: https://www.stralsakerhetsmyndigheten.se/en/

19. Public Health England (2018) National Diagnostic Reference Levels (NDRLs): 15 November 2018 onwards. Available from: https://www.gov.uk/ government/publications/diagnostic-radiology-national-diagnosticreference-levels-ndrls/ndrl

20. Schegerer A, Loose R, Heuser L, Brix G (2019) Diagnostic Reference Levels for Diagnostic and Interventional X-Ray Procedures in Germany: Update and Handling. Rofo. 191(08):739-751 Available from: http://www.thiemeconnect.de/DOI/DOI?10.1055/a-0824-7603

21. Treier R, Aroua A, Verdun FR, Samara E, Stuessi A, Trueb PR (2010) Patient doses in CT examinations in Switzerland: implementation of national diagnostic reference levels. Radiat Prot Dosimetry. 142(2-4):244-254 Available from: http://rpd.oxfordjournals.org/content/142/2-4/244.abstract

22. Castellano IA, Nicol ED, Bull RK, Roobottom CA, Williams MC, Harden SP (2017) A prospective national survey of coronary CT angiography radiation doses in the United Kingdom. J Cardiovasc Comput Tomogr. 11(4):268-273 Available from: https://doi.org/10.1016/j.jcct.2017.05.002

23. Foley SJ, McEntee MF, Rainford LA (2012) Establishment of CT diagnostic reference levels in Ireland. Br J Radiol. 85(1018):1390-1397

24. Fukushima Y, Tsushima Y, Takei H, Taketomi-Takahashi A, Otake H, Endo K (2012) Diagnostic reference level of computed tomography (CT) in Japan. Radiat Prot Dosimetry. 151(1):51-57

25. Hausleiter J, Meyer T, Hermann F et al (2009) Estimated Radiation Dose Associated With Cardiac CT Angiography. JAMA 301(5):500-507 Available from: http://jama.jamanetwork.com/article.aspx?doi=10.1001/jama.2009.54

26. Japan Network for Research and Information on Medical Exposures (2015) Diagnostic Reference Levels Based on Latest Surveys in Japan — Japan DRLs 2015. Available via http://www.radher.jp/JRIME/report/ DRLhoukokusyoEng.pdf.

27. Kanal KM, Butler PF, Sengupta D, Bhargavan-Chatfield M, Coombs LP, Morin RL (2017) U.S. Diagnostic Reference Levels and Achievable Doses for 10
Adult CT Examinations. Radiology 284(1):120-133 Available from: http:// pubs.rsna.org/doi/10.1148/radiol.2017161911

28. Mafalanka F, Etard C, Rehel JL et al (2015) Establishment of diagnostic reference levels in cardiac ct in france: A need for patient dose optimisation. Radiat Prot Dosimetry. 164(1-2):116-119

29. Palorini F, Origgi D, Granata C, Matranga D, Salerno S (2014) Adult exposures from MDCT including multiphase studies: First Italian nationwide survey. Eur Radiol. 24(2):469-483

30. STUK (2013) Reference levels for patient radiation exposure in computed tomography examinations of adults. Available via https://www.stuk.fi/ documents/88234/1106801/decision-2-3020-13-23-5-2013-referencelevelsfor-patient-radiation-exposure-in-computed-tomography-examinationsofadults.pdf/71ee0d51-ff7b-49e7-9ceb-fee01d56454d.

31. Salama DH, Vassileva J, Mahdaly G et al (2017) Establishing national diagnostic reference levels (DRLs) for computed tomography in Egypt. Phys Medica 39:16-24 Available from: http://linkinghub.elsevier.com/retrieve/pii/ S1120179717301679

32. NCS (2012) Diagnostische referentieniveaus in Nederland.

33. Gershan V, Homayounieh F, Singh R et al (2020) CT protocols and radiation doses for hematuria and urinary stones: Comparing practices in 20 countries. Eur J Radiol 126:108923 Available from https://doi.org/10.1016/j. ejrad.2020.108923

34. Smith-Bindman R, Wang Y, Chu P et al (2019) International variation in radiation dose for computed tomography examinations: Prospective cohort study. BMJ. 364:1-12

35. De Mello-Amoedo CD, Martins AN, Tachibana A, Pinho DF, Baroni RH (2018) Comparison of radiation dose and image quality of abdominopelvic CT using iterative (AIDR 3D) and conventional reconstructions. AJR Am J Roentgenol. 210(1):127-133

36. O'Neill S, Kavanagh RG, Carey BW, Moore N, Maher M, O'Connor OJ (2018) Using body mass index to estimate individualised patient radiation dose in abdominal computed tomography. Eur Radiol Exp 2(1):0-7

\section{Publisher's Note}

Springer Nature remains neutral with regard to jurisdictional claims in published maps and institutional affiliations.

\section{Submit your manuscript to a SpringerOpen ${ }^{\circ}$ journal and benefit from:}

- Convenient online submission

- Rigorous peer review

- Open access: articles freely available online

High visibility within the field

- Retaining the copyright to your article

Submit your next manuscript at $>$ springeropen.com 